tion and answer in this series covers most of the ground. Although of little value to the student who has not previously studied his subject in the ordinary textbooks, these volumes will be most valuable for emphasizing the essential points.

Menical Diseases in Children. By D. N.

Nicholson, M.B., M.R.C.P. Pp. 74.

Price Is. 6d.

This little book, which is one of the Catechism Series, presents the essential facts on " Diseases of Children," and it is intended for the student about to enter for his final examination. As in the other volumes of this series the book is arranged in the form of question and answer. 'The first chapter deals with the physiology of infancy, and includes useful information about feeding. The various systems are then dealt with, and the book concludes with a valuable chapter on prescriptions and directions as to making various foods, such as albumen water. It is easy to read and can be recommended to the student who wishes to refresh his memory.

Psychology. By J. H. Ewen, M.R.C.S., L.R.C.P., D.P.H. Pp. 72. Price Is. 6d.

This volume will be read with considerable interest not only by those who intend to make a special study of psychology but by every student of medicine. It is one of the Catechism Series and is arranged in the form of question and answer. In the ordinary medical examination the student is not expected to have a deep knowledge of psychology and this subject is sadly neglected. At the same time a knowledge of human nature, of conduct and of the mental outlook found in human nature is an absolute necessity to anyone who would be a successful physician. For a deep knowledge of this important and fascinating subject the student should refer to the textbooks and very large literature on the subject, but in order to obtain a general idea of psychology and a knowledge not only of the elemental facts, but of the direction in which progress is being made, this little volume can be highly recommended.

\section{Fellowship of Medicine}

\section{IND \\ Post-Graduate}

\section{Medical Association}

\author{
Telephone: Mayfair 2288.
}

The following facilities are offered:-

I. Comprehensive tickets admitting to the daily practice of some 40-50 General and Special Hospitals. 1 week to 1 year. Fees : \$2/2/0 to \$21. Special arrangements made for part-time study.

II. Intensive Courses in Medicine and Surgery, and in Special subjects. 1-4 weeks, Fees \$1/1/0 to $\$ 7 / 7 / 0$. List for 12 months available.

III. Annual Membership Subscription: 10/- includes "Post-Graduate Medical Journal," and monthly lists of lectures and demonstrations.

For copies of all syllabuses, and for information regarding Post-Graduate work in Great Britain and Ireland, apply to:

THE SECRETARY, FELLOWSHIP OF MEDICINE, 1, Wimpole Street, London, W. 1.

\section{SPECIAL COURSES}

\section{DECEMBER.}

53. Dermatology. Dec. 2 to Dec. 14 . Blackfriars Skin Hospital. Afternoons. Fee $\& 11$ s. Od.

54. Diseases of Infants. Deo. 2 to Dec. 14. Infants Hospital. Afternoons. Fee £3 3s. Od.

55. Practitioners' Course. Dec. 2 to Dec. 14. L o nd o

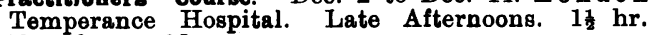
Fee $\& 1$ 1s. Od.

\section{JANUARY, 1930.}

Cardiology. Jan. 13 to Jan. 25. National Hospital for Disesses of the Heart. All day. Fee $£ 77 \mathrm{~s}$. Od. (limited to 20).

Diseases of Children. Jan. 13 to Jan 25. Queen's Hospital. All day. Fee $£ 3$ 3s. Od.

Medicine, Bursery and the specialities. Jan. 27 to Feb. 8. Prince of Wales's General Hospital Group. All day. Fee 255 s. Od.

Copies of the Syllabuses of above Courses and tickets of admission can be obtained from the Secretary to the Fellowship of Medicine, 1, Wimpole Street, W. 1. 